ble que se trate de una invención del monje de Arlanza. Es hecho bien conocido que las mocedades de los héroes épicos no se encuentran consignadas en los documentos de carácter histórico, y que lo que sobre ellas se escribió no es sino obra de la ficción. Igual cosa habrá ocurrido con Fernán González. También es sabido que las refundiciones en prosa de las epopeyas españolas cambian a menudo las narraciones originales. La de 1944 lo hace con Fernán González, intercalando dos capítulos en el relato del Poema. Esta adición contiene el episodio de las "vistas de Carrión" entre el conde castellano y el rey Sancho I de León, en que éste es salpicado de agua y arena por el caballo de Fernán González. El refundidor hizo caso omiso de la actitud de respeto y obediencia que el héroe del Poema observa siempre para con su monarca; destruyó así uno de los propósitos fundamentales del poeta. También eliminó el contraste entre las condiciones ínfimas en que vemos por vez primera al joven y las alturas a que después llega: al sustituir al "carbonero" por un "cavallero" hizo más digna de respeto la crianza del Conde, pero cambió el tono y la significación del episodio.

Resumiendo: para ensalzar las hazañas de su héroe, el autor del Poema de Fernán González adornó el relato de sus mocedades con elementos ficticios que tomó de ciertas leyendas medievales. Como el Paris del Libro de Alexandre, el joven Fernán - ¿imitación? ¿coincidencia?es robado y criado en las montañas por gentes rústicas; como en una versión de la vida de San Eustaquio - aquí la imitación es evidente-, el que lo cría es un carbonero. El folklore literario ha venido a remediar así la pobreza de los documentos históricos.

Albion College,

J. P. KeLLER

Albion, Michigan.

\title{
SOBRE LA SELECCIÓN ARTÍSTICA EN EL QUIJOTE: “...LO QUE HA DEJADO DE ESCRIBIR" (II, 44)
}

En la gestación de toda obra de arte hay una fuerza intencional que obliga al artista a llevar a cabo una selección en sus materiales. Este aspecto de la creación ya se ha estudiado en Cervantes, pero la perenne vitalidad de su obra maestra nos invita a volver a ella siempre de nuevo. Las consideraciones que siguen se fundan en la observación de un fenómeno que se da también en otros artistas, pero que cobra en el Quijote una significación especial, debido al carácter innovador de la obra, hito decisivo en la evolución de la novela moderna. Nos referimos al hecho de que Cervantes tiene a veces la preocupación de llamar la atención del lector, directa o indirectamente, sobre materias que ha eliminado o pasado por alto; indicaciones preciosas porque dejan entrever, aunque sólo sea de pasada, cómo concebía el autor su empresa artística.

Dado el carácter paródico del Quijote - exclusivo al comienzo, y luego cada vez más accesorio-, las menciones de materias omitidas tienen a veces un tono festivo y hasta una formulación al parecer ambigua. Reflejan, sin embargo, una esencial preocupación por establecer las cosas que han de tener cabida. No se trata, claro está, de una actitud doc- 
trinal excluyente; no hemos de convertir a Cervantes en un teórico de la composición. Pero sí podemos observar una y otra vez cómo, bajo el impulso que le comunica la obra misma mientras la va componiendo, se hace en él más urgente aquella preocupación, sin que, por lo demás, pierda nunca su carácter problemático. Cervantes trata de encajar la cuestión en el sistema aristotélico, pero es evidente que se mueve con plena autonomía dentro de tal sistema, aprovechando lugares comunes aristotélicos para fines artísticos propios que varían según la ocasión, expresándose con mayor o menor seriedad y no sin vacilaciones. A veces siente impulsos de salirse por completo del casillero aristotélico, como cuando observa, en el prólogo de la Primera parte (escrito después de concluida ésta), que Aristóteles "nunca se acordó" de los libros de caballerías, y mucho menos de un libro que era "todo él ... una invectiva" contra ellos.

Con todo, un rasgo convencional de los libros de caballerías, la existencia de un fingido autor original sabio o mágico, es el que servirá a Cervantes, ya muy avanzada la Segunda parte, como recurso para someter su obra a la prueba de la doctrina crítica de la Poética de Aristóteles según le ha llegado a través de sus comentadores italianos y españoles. En cierto momento, Cide Hamete Benengeli termina pidiendo que "no se desprecie su trabajo, y se le den alabanzas no por lo que escribe, sino por lo que ha dejado de escribir" (II, 44; t. 6, p. 268) ${ }^{1}$. Aunque en el lenguaje se trasluce cierta vacilación, la idea que Cervantes quiere expresar no deja lugar a dudas: reconoce que está obrando en el Quijote un principio que lo obliga a mantener en un enfoque constante las dos figuras centrales, "sin osar estenderse a otras digresiones y episodios más graves y más entretenidos" "2. Si se comparan las palabras de Cide Hamete con las del Canónigo de Toledo acerca del carácter del libro de caballerías ideal, se ve que en ambos casos el criterio es aristotélico. El Canónigo había aludido a la "proporción de [las] partes con el todo", a una variedad no reñida con la unidad, a la verosimilitud en los sucesos y las situaciones (I, $47 ;$ t. 3 , pp. $347-35^{\circ}$ ). Son las mismas preocupaciones de Cide Hamete, quien sólo admite, para dar variedad a la obra, los temas de entretenimiento que surjan al narrar las hazañas de don Quijote: "episodios... nacidos de los mesmos sucesos que la verdad ofrece".

Claro que Cervantes no equipara el Quijote con la obra ideal imaginada por el Canónigo: la diferencia estriba precisamente en "lo que ha dejado de escribir". De propósito renuncia Cervantes al marco amplísimo que el Canónigo imaginaba, a aquel "largo y espacioso campo por donde sin empacho alguno pudiese correr la pluma", y habla ahora de

1 Citamos por la última edición de Rodríguez Marín, Madrid, 1947-1949.

2 Claro es que Cervantes no ha llegado a formular tal concepto de la obra sin la cooperación de su público, esto es, sin tomar en cuenta la reacción de los lectores de la Primera parte. Recuérdese lo dicho por Sansón Carrasco (II, 9; t. 4, p. 91): "Una de las tachas que ponen a la tal historia... es que su autor puso en ella una novela intitulada aEl curioso impertinente», no por mala ni por mal razonada, sino por no ser de aquel lugar, ni tiene que ver con la historia de su merced del señor don Quijote". Desde un principio, pues, ciertos lectores sentían que no convenía al carácter del Quijote la intercalación de novelas, cuentos o episodios ajenos, a pesar de que ese recurso estaba muy de boga entonces en la prosa narrativa de alguna extensión. 
los "estrechos límites de la narración" en que Cide-Cervantes "se contiene y cierra". Se percibe cierto orgullo de artista en las palabras de Cide Hamete, que ha sabido atenerse a la ley estética inherente a su obra, como el asceta que, al renunciar a lo mundano, siente robustecerse su fibra moral. Lo cual no impide que la idea de aquello a que ha renunciado lo siga tentando, y que Cide-Cervantes se muestre impaciente por haberse echado a cuestas "una historia tan seca y tan limitada como ésta de don Quijote".

Sin embargo, es claro que Cervantes - por lo menos en este momento culminante- admite para su obra la posibilidad de alcanzar algo de dignidad literaria dentro de lo que había sido la esfera épica de Aristóteles, esfera en que la crítica de la época colocaba ya las llamadas "fábulas milesias" ${ }^{3}$. Si Aristóteles no se acordó de los libros de caballerías, la fórmula ideal del Canónigo podía darles carta de ciudadanía neo-aristotélica (a propósito de ellos observa, en efecto, que "la épica tan bien puede escrebirse en prosa como en verso"). Ahora, frente a su propia obra, Cervantes parece concebir todavía otra posibilidad más modesta, por cierto, que la soñada por el Canónigo (a la cual apuntaría el Persiles), pero de logro artístico sustancial y válido.

El empeño de eliminar lo artísticamente inoperante se relaciona con la fundamental cuestión neo-aristotélica de la historia y la poesía, cuyo papel dentro del mundo artístico cervantino demostró por primera vez Toffanin*. Como es sabido, el erudito italiano vio en el Quijote una genial solución artística al dilema teórico, tan angustioso para la crítica de la época, de la incompatibilidad del mundo universal de la poesía con el particular histórico. La solución cervantina, producto de una intuición surgida, según parece, casi al azar, consistía en situar el dilema en la entraña misma de la obra, haciendo que cobrara virtualidad artística por medio de la problemática relación vital entre don Quijote y Sancho. Se funden así las zonas antes separadas de la historia y la poesía, y los particulares adquieren una proyección poética universal.

Basándose en Toffanin, Américo Castro (op. cit., p. 33) utilizó el concepto de relicta circumstantia (frase de Robertelli en su comentario a la Poética, 1548) para ilustrar el proceder artístico de Cervantes en algún pasaje descriptivo o narrativo. Quisiéramos ahora confrontar las observaciones de los dos críticos con lo apuntado arriba sobre las omisiones intencionales del autor, para distinguir con más exactitud el sentido que tiene su selección artística. En la práctica, Cervantes amplía el concepto de relicta circumstantia, pues elimina circunstancias (detalles, acciones), no sólo del mundo prosaico de lo cotidiano, sino del mundo épico-novelesco. Veamos unos casos en que alude a lo que no incluye o no debía haber incluido; tendremos así una nueva demostración de cómo se sitúa su arte nuevo y ecléctico entre los dos extremos del antiguo. (Estos casos se dan tanto en la Primera parte como en la Segunda, pues la eliminación de circunstancias épicas o prosaicas venía practicándose en la obra antes de que Cervantes empezara a pensar en su significación).

${ }^{3}$ Cf. Américo Castro, El pensamiento de Cervantes, Madrid, 1925 , pp. 22 y 44-45.

4 G. Torfanin, La fine dell'umanesimo, Torino, 1920, cap. 15 . 
Ya en la primera aventura hay un pasaje que nos interesa. Al ver don Quijote una venta, el narrador aclara que se le hace "un castillo con sus cuatro torres y chapiteles de luciente plata..., con todos aquellos adherentes que semejantes castillos se pintan" (I, 2; t. 1, p. 110). Cervantes renuncia a la descripción detallada de un castillo novelesco; unos cuan. tos detalles típicos le bastan para evocar en sus lectores - que lo son tam. bién de libros de caballerías- todos los "adherentes" consabidos. Prescinde, pues, de las circunstancias, ya que su narración va dirigida hacia el hecho incontrovertible de que ese edificio es una venta. Pero al entrar don Quijote en esta o en otra venta, o al dar cuenta Sancho de una em. bajada ante Dulcinea, sí aparecerán algunos "adherentes" épicos, aunque sólo en función de la locura de don Quijote o de la reacción de Sancho. Es decir, tratándose de una descripción enumerativa, Cervantes los pasa por alto; sólo les da cabida cuando se convierten en índice de una visión problemática del mundo, reveladora de la manera de ser de los dos personajes.

Por otra parte, si Cervantes, respetuoso de la fantasía de don Quijote, deja que ésta se eche a volar libre de toda traba que lo ate a la acción, el hidalgo nos regalará con un verdadero lujo de detalles épicos, sacados enteramente de su mundo interior; por ejemplo, los que despliega ante los ojos asombrados del Canónigo de Toledo: "Acullá de improviso se le descubre un fuerte castillo o vistoso alcázar, cuyas murallas son de macizo oro, las almenas de diamantes, las puertas de jacintos; finalmente él es de tan admirable compostura, que, con ser la materia de que está formado no menos que de diamantes, de carbuncos, de rubíes, de perlas, de oro y de esmeraldas, es de más estimación su hechura" (I, 5o; t. 3, p. 386 ).

Que la eliminación de circunstancias inútiles era, en el concepto de Cervantes, elemento esencial del arte de narrar, lo comprueba la conseja que cuenta Sancho la noche de los batanes. Sólo que ahora la demostración se hace al revés, mediante un trueque humorístico. Nos encontramos, en efecto, ante un amontonamiento de detalles improductivos -detalles que, puestos en boca de Sancho, provienen del mundo de la his toria. Don Quijote ha de llevar cuenta exacta de las cabras que pasan el río; no debe escapársele ni una sola. Pero no tarda en impacientarse y en perder así la cuenta. Inmediatamente declara Sancho que el cuento se ha acabado. " $¿$ Tan de esencia de la historia es saber las cabras que han pasado?”, pregunta el hidalgo, incrédulo, y añade con ironía deliciosa: "Dígote en verdad... que tú has contado una de las más nuevas consejas, cuento o historia, que nadie pudo pensar en el mundo, y que tal modo de contarla ni dejarla jamás se podrá ver ni habrá visto en toda la vida, aunque no esperaba yo otra cosa de tu buen discurso" (I, 20; t. 2, pp. 102-103). En efecto, esto es llevar la historia (la no-poesía) a extre mos absurdos: Sancho, prosaico, es incapaz de renunciar a una sola circunstancia. Podría decirse que, para don Quijote, la historia-cuento se convierte, por exceso de detalles inertes, en historia-crónica. Su protesta, por otra parte, es también la del héroe épico contra un mundo histórico que ie imposibilita la aventura.

Mucho más tarde, en la Segunda parte, al llegar don Quijote a casa de don Diego de Miranda, consigna Cervantes algunos detalles típicos de 
las casas de aldea ("ancha como de aldea...", etc.) y luego escribe, refiriéndose a Cide Hamete: "Aquí pinta el autor todas las circunstancias de la casa de don Diego, pintándonos en ellas lo que contiene una casa de un caballero labrador y rico; pero al traductor desta historia le pareció pasar estas y otras semejantes menudencias en silencio, porque no venían bien con el propósito principal de la historia, la cual tiene más fuerza en la verdad que en las frías digresiones" (II, 18; t. 5, pp. 59-6o) .

No predomina en esta intervención del moro el tono humorístico típico de sus anteriores apariciones. El pasaje demuestra principalmente cómo ha ido modificándose, a medida que avanza la novela, el papel de Cide Hamete. Porque éste fue creado con intención paródica: para reinvindicar la supuesta historicidad del Quijote, como la reivindicaban para sus libros los autores de novelas caballerescas. Pero Cervantes, después de presentar el Quijote como traducción fiel de un manuscrito histórico, llega a servirse aquí de esa ficción histórica para demostrar, no que la historia española de don Quijote sea réplica exacta de la arábiga, sino que es de índole distinta. (Se abre, con esto, otra de aquellas múltiples perspectivas tan características de la urdimbre de la Segunda parte). Se contrapone a la historia-crónica de Cide Hamete algo que el traductor sigue llamando "historia", aunque sabe que tiene ya otro carácter, puesto que siente la conveniencia de "pasar en silencio" las "menudencias" de la crónica. Todavía conserva cierta ambigüedad el pasaje, porque en él los términos "historia" y "verdad" se refieren no sólo al original de Cide Hamete, sino también a la supuesta traducción hecha por Cervantes. De cualquier modo que sintiera Cervantes la diferencia esencial entre el Quijote y la crónica imaginaria, le faltaba un término para precisarla, y se sirvió de la palabra "historia", cuya significación abarcaba tanto las narraciones "fingidas" - breves o de cierta extensión- como las crónicas. Otra ambigüedad se debe al hecho de que la intención paródica subsiste aún, aunque no sea la predominante, y que los "adherentes" suprimidos (relicta circumstantia) se llaman "frías digresiones"; la traducción de Cervantes (que habíamos creído libre) cobra así visos de veracidad mayor que el original. Como se ve, mediante un fino espejismo irónico juega Cervantes con dos conceptos opuestos brotados de las entrañas de unas mismas palabras, señal de la despreocupación con que adapta los términos aristotélicos a sus propios fines y señal también de su sensibilidad lingüística.

Lo que queda firme bajo el cambiante juego irónico de este pasaje es la conciencia cervantina de que ciertos detalles prosaicos, como los de la casa de don Diego de Miranda, enumerados descriptivamente, tienen tan poco que ver con sus propósitos artísticos como aquellos otros de los castillos épicos que don Quijote creía ver en el camino. Es de notar cómo, en vez de callar sencillamente las circunstancias de la casa de don Diego, Cervantes alude de intento a ellas para decirnos que no las va a reproducir. Recordemos ahora que un poco más adelante, estando todos a la mesa, observa Cervantes que "de lo que más se contentó don Quijote fue del maravilloso silencio que en toda la casa habia, que semejaba un monasterio de cartujos" (II, i 8; t. 5, p. 67). Es el único detalle descriptivo de la casa que se nos da en todo el capítulo, aparte los rápidos 
trazos genéricos del comienzo. Así, este sencillo detalle ambiental suple todas las circunstancias "pintadas" por Cide Hamete y omitidas por su traductor. Se siente en seguida que el "maravilloso silencio" de la casa no es una circunstancia de ese tipo. Su poder de evocación es tal, que hace surgir ante nosotros la casa toda, no como pintura o representación, sino como sensación o experiencia. He aquí la auténtica poesis cervantina, que se eleva con proyección universal sobre los particulares detalles cotidianos -y proyección también del estado de ánimo de don Quijote. No es preciso meterse en el intrincado laberinto del problema de la conciencia artistica de Cervantes para afirmar que un mismo principio de selección rige la supresión de unos detalles y la incorporación de otros en este capítulo. ¿Será que a estas alturas de la novela el arte narrativo de Cervantes va tomando efectivamente conciencia de sí mismo?

A decir verdad, se podría creer que ya desde antes venía haciéndolo. Recuérdese aquella conversación (II, 3 ; t. 4, pp. 85-86), ya notada por Toffanin y Castro, en que don Quijote, Sancho y Sansón Carrasco hacen un examen crítico del Quijote de 1605. Observa Sansón que algunos lectores

se holgaran se les hubiera olvidado a los autores... algunos de los infinitos palos que en diferentes encuentros dieron al señor don Quijote.

- Ahí entra la verdad de la historia -dijo Sancho.

--También pudieran callarlos por equidad -dijo don Quijote-, pues las acciones que ni mudan ni alteran la verdad de la historia no hay para qué escribirlas, si han de redundar en menosprecio del señor de la historia. A fee que no fue tan piadoso Eneas como Virgilio le pinta, ni tan prudente Ulises como le describe Homero.

Y en seguida cita Sansón la famosa distinción aristotélica entre el poeta y el historiador.

¿Es historia o poesía el Quijote? Se ventilan las posibilidades según la pauta aristotélica, quedando la cuestión en el aire, pues cada uno de los personajes se mantiene en su punto de vista y el dilema se suma a su vida, resulta un aspecto más de su ser. Para Sancho, los palos son garantía de una veracidad como de crónica: ni uno ha de omitirse. La opinión a que alude el Bachiller parece decir que los palos, por "infinitos", resultan inverosímiles, dando a entender que el Quijote ha de considerarse como poesia. Para don Quijote no hay duda posible: él es "el señor de la historia", es decir, el héroe épico; "la verdad de la historia" no depende de que se registre con exactitud cada acción suya. Es evidente que, en su boca, "verdad" e "historia" equivalen casi a "verosimilitud" y "fábula", mientras que Sancho entiende los términos al pie de la letra. En este pasaje, por ser diálogo - casi podriamos decir dialéctica-, la distinción anotada entre los diversos sentidos de ambos términos se desenvuelve casi analíticamente.

Aunque la cuestión historia-poesía queda pendiente, en cuanto doctrina, precisamente porque no cabía un libro como el Quijote dentro de tal esquema de posibilidades, no hay duda de que Cervantes, como creador, al escribir la Segunda parte, toma más en cuenta el parecer de don Quijote y el de los lectores citados por Sansón, que el de Sancho. ¿Encontraría que el elemento de farsa que asomaba en los episodios de palos, como 
resabio de la primera intención caricaturesca, debía suprimirse ahora que la historia había rebasado esa intención? Suprimirse por completo. de seguro que no: nunca llega a desaparecer ese ingrediente. Pero sí atenuarse. Al escribir la Segunda parte se adelanta Cervantes a satisfacer parcialmente las objeciones del héroe y de los lectores del único modo como puede hacerlo un autor: omitiendo los detalles o situaciones que no logran convencer, o, como dice el Canónigo, que no "casan con el entendimiento" del lector. Hasta la llegada al castillo de los Duques (cap. $30)$, los protagonistas casi no sufren violencia física alguna ${ }^{5}$. Verdad es que mientras permanecen en él vuelven a aparecer los palos -o su equivalente-, y que más tarde reincide Cervantes en la manera inicial con verdadera crudeza, cuando hace que caballero y escudero sean hollados por bueyes y cerdos. En tales episodios no piensa el autor en "facilitar imposibles" - frase del Canónigo- para provocar aquella "suspensión de la incredulidad" de que habla Coleridge en frase que Cervantes hubiera entendido perfectamente. Están en otro plano de farsa pura. Tales momentos le restan algo de humanidad a don Quijote, pero permanecen aislados. La verdadera humillación que él sufre y que le lleva al desengaño es de índole moral, y en ésta sí participamos nosotros, sea cual fuere nuestra reacción. Las inverosímiles violencias no alcanzan a desvanecer el efecto total de verdad ideal, es decir, de verosimilitud, logrado con un reposo y una hondura que no sentimos en la Primera parte.

En los últimos capítulos es como si nos despidiéramos por segunda vez del mundo épico, pues Cervantes cuenta que, al apearse en un mesón, "por tal le reconoció don Quijote, y no por castillo de cava honda, torres, rastrillos y puente levadiza" (II, 71; t. 8, p. 219). El que el autor acorte los detalles épicos no ofrece novedad alguna. Lo que ha variado es la postura de don Quijote, y esto hace que aquellos detalles cobren mayor intensidad poética: con ellos vemos alejarse un mundo épico, no ya de la fantasía del autor, sino de la del héroe. Un vigor poético nuevo, distinto del antiguo, viene a reanimar esa vieja materia épica, cuyo poder de evocación estaba casi exhausto, al reflejarse en ella el estado de ánimo desfalleciente del héroe, figura ahora más que nunca universal. Aquellos detalles adquieren así una nueva proyección poética, lo mismo que los detalles ya vistos del mundo real.

Alan S. Trueblood

Brown University.

- A no ser que incluyamos la inmersión en el Ebro, la única excepción son los palos que le dan a Sancho los del pueblo del rebuzno (II, 27). En este caso, don Quijote consigue por sí mismo, mediante una oportuna retirada, que los palos no le toquen a él. 